\title{
Testing for Panel Granger Causality Relationship between international R\&D cooperation and Economic Growth
}

\author{
Tarek Sadraoui ${ }^{1}$, Tarek Ben $\mathrm{Ali}^{2}$ \\ ${ }^{1}$ MODELIS University of Sfax, HIAS University of Gafsa \\ tarek.sadraoui@gmail.com \\ ${ }^{2}$ University of Gafsa, Economic Department HIAS Gafsa
}

tarek.benal@yahoo.fr

\begin{abstract}
In this paper we investigate the causal relationship between R\&D cooperation and economic growth. We use an innovative econometric method which is based on a panel test of the Granger non causality hypothesis. We implement various tests with a sample of 32 industrial and developing countries over the 1970-2012 periods. The results provide support for a robust causality relationship from economic growth to the R\&D cooperation. On the contrary, the non causality hypothesis from $R \& D$ cooperation to economic growth can't be rejected in most of the cases. However, these results only imply that, if such a relationship exists, it can't be easily identified in a simply bi-variate Granger causality test.
\end{abstract}

\section{Keywords}

Granger Causality Tests; Dynamic Panel Data; R\&D cooperation; Economic Growth; Spillovers.

\section{Academic Discipline And Sub-Disciplines}

Quantitatives Method , Economic Growth, Econometric of panel data.

\section{SUBJECT CLASSIFICATION}

$91 \mathrm{G} 70$; 91B62; $91 \mathrm{~B} 44$

\section{Council for Innovative Research}

Peer Review Research Publishing System

Journal: International Journal of Management \& Information Technology

\author{
Vol. 7, No. 3 \\ editor@cirworld.com \\ www.cirworld.com, member.cirworld.com
}




\section{INTRODUCTION}

R\&D is a cumulative acquisition process of competences and know-how. The transfer of tacit knowledge is delicate and represents a specific characteristic of R\&D. Moreover, certain expenditure is obligatory to R\&D such as capital expenditures, infrastructures are irrecoverable. It is for that investment in $R \& D$ is an irreversible investment and subjected to an uncertainty. From uncertainty of cumulative process (R\&D) is born a dynamic behaviour from information search which relates to nature of goods. However, the impact of technology creation process and diffusion on economic growth and the role of public administrations remains until our days less understood.

Today, countries are confronted with structural changes which imply the reconstitution of production systems. Organizations forms which have allowed industrial development during the last two centuries must be reconfigured to the new technological economic and institutional challenges. Indeed, if technological and organisational change are necessarily localised as suggests Antonelli, operating with proximity of accumulated knowledge, it also passes by examination of new horizons according to March implying new competences to some internalized degree and required by cooperation. In this level, an interesting question appears: why $R \& D$ cooperation and up to what point this one led to improve productivity to build a favourable framework to economic growth of countries?

Technological cooperation remains one of economic reality which knows a notable growth since the beginning of the Eighties. One of the first and major contributions to theoretical literature on R\&D cooperation is that of Katz. In Katz model, social benefit of the R\&D cooperation depends mainly on two factors. The first is spillovers level (technological externalities) in this model, the effective R\&D effort of a country within a cooperative structure corresponds to the sum of its own effort in expenditure R\&D and provided efforts by partners countries in spillovers. Thus, since these spillovers are internalizes within a cooperative structure, those profits jointly with participating countries in the agreement and raise consequently the levels of effective R\&D effort. This increase in innovation effort resulted reducing costs, increasing production levels and lowering prices.

This paper is structured as follows: The next section describes literature on R\&D cooperation which we indicate reason and base of knowledge to make. In particular, we analyze the conditions under which R\&D cooperation makes more advantageous development of technological innovation. Indeed, this paper calls into question our problems and constitutes a general synthesis of the relation between $R \& D$ cooperation and economic growth.

\section{LITERATURE ON R\&D COOPERATION}

$R \& D$ Cooperation belongs to the new developed strategies by countries in more globalize and competitive economic environment. The advantages of R\&D cooperation for the participating countries are well-known. Countries engaged in $R \& D$ cooperation can profited from economies scale. Indeed, they can also benefit from the complementarities of their know-how and can avoid repetitions of their results. Another advantage of R\&D cooperation is internalisation of "spillovers", due to the fact that patents do not reflect a perfect protection against imitations. The importance of cooperative research is recognized through the policies of certain governments. In particular search for projects in common runs "Research Joint Venture" (RJV) is guaranteed by the antitrust privilege acts and their formation is encouraged by subsidies. The reasons for cooperation are expensive and risky. Moreover, cooperation can increase efficiency, such as economy scale in production Veugelers.

This paper is dealing with R\&D cooperation. Indeed, several aspects of cooperative R\&D were studied in economic literature. Theoretical literature analyzed intensively how "spillovers" affect investment in R\&D in a cooperative situation compared with competition (no cooperation). Moreover, theoretical literature treats the stability search for joint project, organisational and asymmetry between partners' researches. As an example, in Japan, industrial policy actively supported consortia formation of research since 1959. The Japanese spectacular growth in Sixties and Seventies were allotted mainly to cooperative research. Consequently, at the beginning of the Eighties American legislations and European increased their efforts of which the goal is to promote and to encourage R\&D cooperation. In the Nineties, the USA increased the budget of advanced technology program which supports research projects combined to encourage common research considerably.

Table 1: The number of participants in co-operative research world enters (1986-2012)

\begin{tabular}{cc}
\hline Year & Number of participant \\
\hline 1986 & 22 \\
\hline 1987 & 15 \\
\hline 1988 & 23 \\
\hline 1989 & 47 \\
\hline 1990 & 217 \\
\hline
\end{tabular}




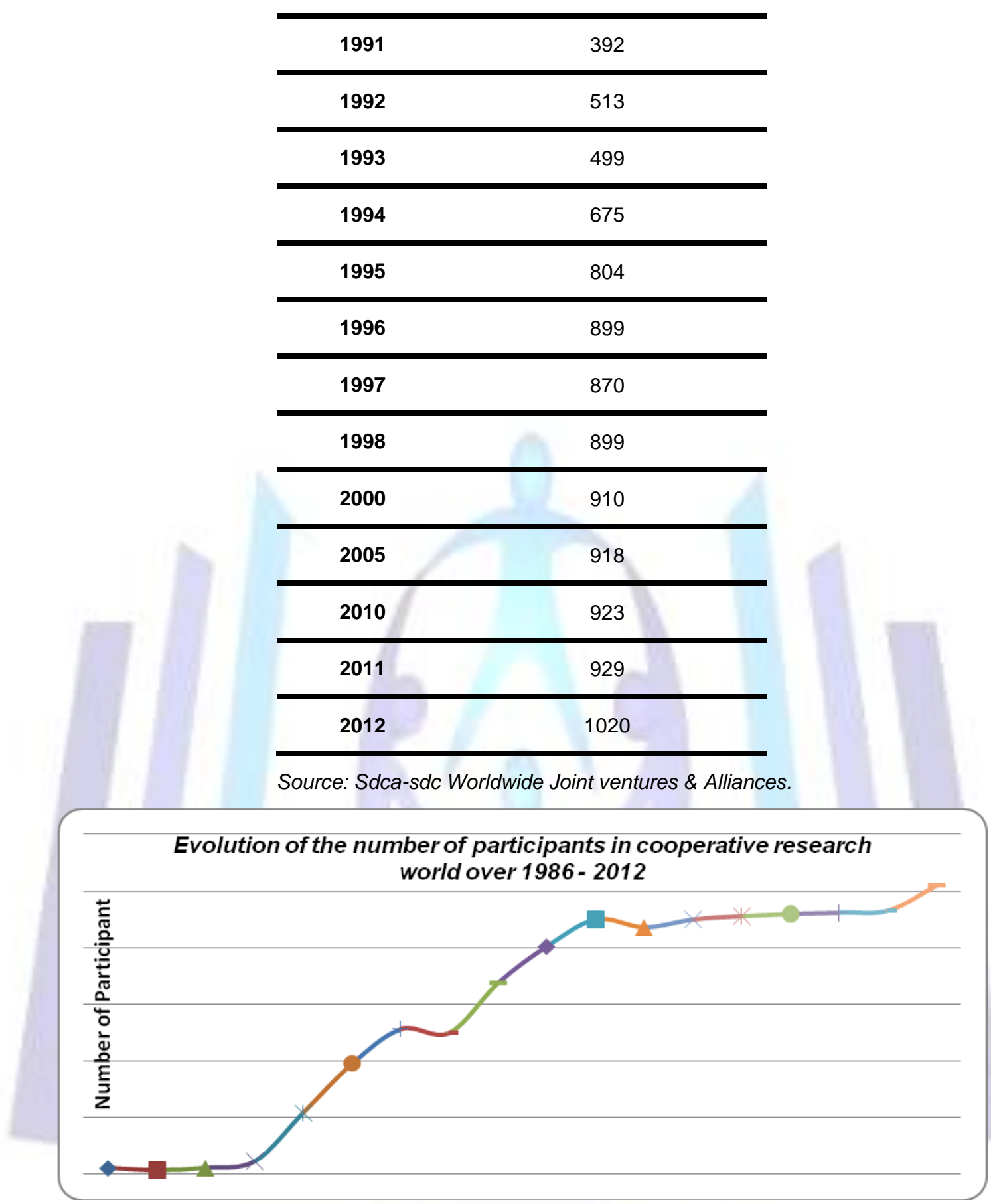

FIG 1: Evolution of the number of participants in cooperative research world over 1986 - 2012

The table and the graph above illustrate the number growing of participant in cooperative research with an initial support from at least one million \$. In 1985, Europeans Commission allocated permission for certain categories of the same R\&D; it authorizes common exploitation of the R\&D results. Moreover, there are several programs established and consolidated by European Commission to encourage R\&D cooperation. The Strategic European program for research in technologies information (SPIRIT) is largest of these programs. Around 9000 organizations took part in more than 1200 Esprit- projects financed over 1983 - 1996.

Geroski summarizes theoretical conclusions on this subject. He concludes that R\&D projects are desirable when technological Spillovers and positive externalities profitable (share of risk) exist. Also, a nonexclusive consortium between companies which begin pro-competitive research is preferable with a cooperative agreement of research between companies on the same production market. According to Geroski discussion, when we evaluate the cooperative R\&D impact we must separate its direct effect on productivity and its indirect effect through research intensity and competition McKelvie, A. and Wiklund, J. Therefore, how does productivity assign R\&D cooperation to the countries which have research joint activity? R\&D can have positive impact on productivity. In fact, in cooperative research event, research productivity is affected. Therefore, the same amount of R\&D investment results more (or less) innovation. Then, if 
competing structure and R\&D investments are non-affected, cooperation in the innovating activities increases (drops) the productivity compared with the case of competing R\&D. This direct effect of R\&D is studied by Baumol.

With the development of the endogenous growth theories, economic analysis indeed highlighted role of knowledge accumulation in technical development, driving progress of growth. But knowledge is not a good like others. It rivet of specific characters which are the origin of externalities in its production and its diffusion. The R\&D cooperation question and intellectual property can be placed in prospect with broader problems for the state role in growth promotion. The majority of endogenous growth models underlined the fact that the growth rate of an economy could be optimized thanks to state intervention to fight against external effects which cause divergence between research of social optimum and individual optimum. Thus, state education role or infrastructures supply could be proposed. In the same spirit, its action can be completely determining to support knowledge accumulation necessary to technical progress.

\section{R\&D COOPERATION AND TECHNOLOGICAL SPILLOVERS}

In R\&D cooperation management, we must distinguish three levels: the development of governmental policy, its implementation strategy (organizations directions and programs directions) and its execution (scientific community). For lack of a clear distinction between these three levels, a certain confusion reigns as for responsibilities for the ones and others, prejudicial confusion with a good cooperation piloting. The international cooperation concept is a very general concept which covers with various realities. In this work, the word cooperation will be used in its broadest direction. R\&D cooperation was also perceived like a potentials associating advisability of research activities with an aim of increasing capacity to be integrated in international economy, and to develop innovation efforts. The technological cooperation became a required organization to have external knowledge access Mowery, Oxley, Silverman,. In addition technological cooperation is perceived like an internalisation vehicle of technological externalities and diffusion effects of associated any research activity. This reflects the idea of D'Asprement. C and A. Jacquemin, Katz. M, and Ordover. J,. These impacts limit the inciting role of market investment in $R \& D$ and innovation.

The limits of various works which is interested in spillovers impact on growth more precisely lead to introduction of technological cooperation interactions, like a diffusion mechanism of externalities. By regarding cooperation as a knowledge creation, two characteristics can be indicated; namely uncertainty and existence of an incomplete contracts, to show that spillovers can circulate within organisational forms.

In Gallié. E optics, cooperation is seen as an externality knowledge vector. It developed a new design of the relation cooperation - externalities, contrary to D'Aspremont and Jacquemin analysis. At this level, economists develop two principal perceptions to knowledge externalities. In standard economy, spillovers are considered as a market failure. Producer cannot be remunerated by production cost. Their existence generates an incentive deficit to invest. The models of D'Asprement and Jacquemin propose to internalize spillovers in cooperation relations to mitigate failures market. The second perception notes that externalities constitute a determining factor of growth Broekel, T. et al,.

The externalities due to research are related to knowledge diffusion: when a country continues an activity of research, a part of produced knowledge is diffused with other countries. These externalities have a strong effect on research output. R\&D activity generates a level of excessive investment compared to what it would be collectively optimal to carry out Crampes,, Broekel, and Graf. The reasons are: Each country wants to be the first to succeed, whereas community is interested only by innovation realization, no matter on its origin. In addition, so many countries take part in research corresponding to the same innovation, which involves a repetition of research efforts.

When technological externalities dominate, the market scale will be characterized by under investment in R\&D. Conversely, when externalities strategic dominate, the market scale is characterized by an over-investment in R\&D. This analysis of research is similar to traditional externalities analysis. Thus, according to externalities modern analysis, research externalities are liable to mechanisms of correction (internalization) in the optics of a convergence between private and public optimum. The first mechanism corresponds to the assistances systems and subsidies to R\&D. The second consists in granting to innovators a right of ownership on the result of their activities. The internalization externalities literature of research admits often assumptions according to which, the failure market involves state intervention and, the innovator has through protection of intellectual property of appropriation knowledge. The problem of externality is not a unilateral problem, but a bilateral problem between the transmitter and the receiver. In the field of knowledge production, creation of collective entities (partnership, consortium) allows also internalized externalities. Thus the question is to amplify the diffusion zone not to have work on knowledge appropriation.

\section{APPROPRIATION OF R\&D COOPERATIVE RESULtS}

Our primarily work aims are to show that cooperation, and in particular R\&D consortia, make to partners possibility to innovate and to adapt scientific and technological results. Starting from an appropriability definition, the principal factors supporting this innovation within consortia in R\&D are emphasized. Econometric analyses show that R\&D consortia produce various results which can be explained by specific methods of cooperation. If R\&D consortia are the subject of an increasing interest, former research was primarily directed towards empirical studies relating to a broad sample of R\&D consortia are still in a very limited number. Moreover, appropriation studies were limited to appropriability problems and legal means giving possibility to the countries of benefiting from their innovations and protecting them from a possible imitation.

The concept of appropriation is useful to include the principal conditions to technological change and innovations realization. Indeed, appropriations used by theorists of ownership, which characterize R\&D like a non appropriable public 
property. Technological innovation will be entirely suitable and transform in economic innovation only under the condition of having an absorption capacity as suggest Cohen $\mathrm{W}$ and Levinthal, in order to be able to integrate know how. Thus appropriation concept refers to two various logics. The first, in general bring closer to economic analysis and of ownership theory. The second is attached to cognitive sciences and evolutionist theories and competences, and refers to training while returning more precisely to absorption capacity. On the other hand, it is sufficient to be limited to absorption capacity to justify research cooperation. If not, which assumption is necessary to adopt cooperate R\&D.

\section{AN EMPIRICAL ANALYSIS BY DYNAMIC PANEL DATA MODELS}

The goal of this analysis is to examine in a structure of dynamic panel data the role of R\&D cooperation in innovation process. Initially, the analysis is focused on the impact R\&D cooperation -in accordance with others factors - on production innovation. Our objective is to show if $R \& D$ cooperation are complementary to innovation process, by increasing innovation and production of companies measured by the intensity of internal R\&D, respectively by innovations realization product. The intensity of internal R\&D stimulates also probability of $R \& D$ cooperation between various countries. The majority of innovation activities imply multiple actors. The development of new products requires an active research process implying several companies and establishments to discover new knowledge sources and technology as suggests DeBresson, ; Nooteboom,; Von Hippel,. The countries which engage in innovation activities are conscious of the need for establishing R\&D cooperation to obtain new products which cannot be produced inside these countries. Such R\&D cooperation is defined as collaborations to achieve a common goal which is to develop new and improved products (of technologies).

In a more or less durable multitude of agreements between two or several associates, credits and activities are linked and combined. Thus, the technological capacities are necessary to develop process innovations. The importance of increased R\&D cooperation regularly thanks to increasing complexity, risks and innovation costs 2 . Within the framework of our analysis we primarily try to specify many objectives: The role played by technological cooperation in justification of investment effort in research and development; In which measurements technological cooperation is perceived like a privileged vector of innovation and incentive to innovate and technological cooperation impact on countries growth (in term of GDP per capita).

\subsection{Empirical literature reviews}

$R \& D$ cooperation belongs to new strategies developed by countries in more globalize and competitive economic environment. The advantages $R \& D$ cooperation for participating countries are well-known. Indeed, the participants $R \& D$ cooperation can profit from, and economies scale complementarities of their know-how and can avoid the repetitions of their results. Another advantage of R\&D cooperation is spillovers internalization, owing to the fact that patents do not reflect a perfect protection against imitations. The cooperative importance of research is recognized through the government's policies. Search for common projects runs in particular "Research Joint Venture" (RJV) is guaranteed by privilege of antitrust acts and their formation is encouraged by subsidies etc.

In the framework of opening of economy world and increasing competition countries develop new strategies. New strategies imply networks of intensive work. The reasons for cooperation are expensive and risky. Moreover, cooperation can increase efficiency, such as economy scale in production. This study concentrates on R\&D cooperation. Within this framework, several aspects of cooperative R\&D were studied in economic literature. The theoretical literature analyzed intensively how spillovers affect investment in R\&D in a cooperative situation compared with competition. Moreover, theoretical literature treats stability of search joint project, organisational design and asymmetry between partner's researches.

In the same way research of joint projects is formed starting from antitrust laws because they are considered to promote productivity. Also, to analyze participation research effects programmes of joint project on productivity is an interesting question. Estimation of total cooperative research advantages is very difficult because cooperation can have an impact on R\&D expenditure. Geroski summarizes theoretical conclusions on this subject. He concludes that R\&D projects are desirable when technological spillovers and positive externalities (share risk) exist. According to Geroski discussion when we evaluate $R \& D$ cooperative impact we must separate his direct effect on productivity and indirect effect through research intensity competition. Therefore, how does productivity affect R\&D cooperation?.

$R \& D$ can have a positive impact on productivity. Therefore, the same amount of investment in R\&D results more (or less) innovation. Then, if $R \& D$ investments are non-affected, cooperation in innovating activities increases productivity compared with case of competing R\&D. This direct effect of joint research and development is studied by Kamien et al., Baumol. The common characteristic of their analysis is that they model innovation process (reduction cost). They present a modelling of innovation process with R\&D spillovers. They clarify an innovation model as a process in two stages where in the first stage knowledge is produced and in the second stage this knowledge is employed to reduce the cost.

A limited number of empirical studies are centred on reasons for participation in research consortia. The only exceptions are Irwin and Klenow studies about productivity carried out an econometric analysis of Japanese research consortia. They found that governmental expenditure of $R \& D$ consortia has leads to increase R\&D expenditure. They measured research production by the number of patents. The increase in productivity implies a direct and positive effect of common research on productivity.

In this paper we study implications of productivity of participation in cooperative research. Moreover, we use a sample of various countries over 1992-2011 where information is available on R\&D expenditure. We try to separate total investment $R \& D$ effect and cooperative research participation on productivity. We try to use generalized moments method developed 
by Arellano and Bond, we control possible endogeneity of independent variable, and while adopting recent econometrics literature of panel data relating to unit roots tests, causality and cointegration. Finally we estimate our model by Full Modified Ordinary Least Square method "FMOLS" and we try to interpret results.

\subsection{Model Presentation}

The models which are interested in cooperative research influence on productivity take account of spillovers effects. These spillovers would be mainly proposed for private research. Public research would not profit from overflow resulting effects from other public institutions. Nevertheless, public spillovers diffusion was sometimes tested upstream in innovation process by introducing external public R\&D into function which determines public R\&D. Association of spillovers terms and cooperation is a little usual. However, as underline it Cassiman B and Veugelers. R any exchange, any transfer is likely to cause spillovers. We consider that cooperation can be used as a spillovers vector because of nonrival character of knowledge and uncertainty of knowledge process. Indeed, knowledge is not subject to the same rules of appropriation as in private sector. In fact, the objective of researchers is not to adapt their discovery to illustrate financial profits but to establish a principle priority, generally thanks to publications. In this case, there exists, established priority, no limit with knowledge diffusion. Cooperation within public networks should support considerably knowledge diffusion published.

Within framework of our study we consider a log-linear Cobb-Douglas product function transformed:

$$
\mathrm{y}_{\mathrm{it}}=\delta_{1} \mathrm{y}_{\mathrm{it}-1}+\delta_{2} \mathrm{~L}_{\mathrm{it}}+\delta_{3} \mathrm{~K}_{\mathrm{it}}+\delta_{4} \mathrm{RJV}_{\mathrm{it}-1}+\delta_{5} \mathrm{RD}_{\mathrm{it}-1}+\gamma_{\mathrm{t}}+\eta_{\mathrm{i}}+\xi_{\mathrm{it}}
$$

For more precision, the basic model examined in our empirical justification is drawn from R\&D cooperation literature. We postulate that GDP per capita engaged by governments is function of R\&D expenditure and R\&D cooperation, capital and labour. The model is presented in the form of log-linear relation between various variables. Thus, we define:

Y: logarithm real GDP per capita for country (i) in the year (t);

$\mathrm{K}$ : logarithm of capital for country (i) in the year ( $\mathrm{t}$ );

$\mathrm{L}$ : labour factor for country (i) in the year (t);

RD: expenditure of research and development ratio to the GDP for country (i) in the year (t); and

RJV: R\&D cooperation expenditure calculated as a Spillover effect.

We try to take account of temporal structure of expenditure and of GDP variables With this intention, we must test the presence of unit root test and if all the series are non stationary I(1) The recent approaches adopted by Im, Pesaran and Shin IPS and by Kao are respectively used for unit root and cointegration test. The first consists in carrying out unit root tests on each series by using Augmented Dickey-Fuller, method Dickey and Fuller,; Davidson and MacKinnon,. We obtain then statistics serving to make unit root test for panel by calculating individual statistics ADF average. This value is compared with simulated breaking values provided by IPS. When it is higher than the value given threshold of significance, null assumption of unit root is rejected.

As for used approach by Kao for Cointegration, it consists in making individual regressions of ordinary least squares (OLS) of $Y$ on RJV and carrying out ADF tests on estimated residues of these series Robert Engle and Granger,. The statistics being used to test null assumption of non-cointegration are obtained by calculating the average of ADF statistics previously obtained. It is compared with breaking values provided by Kao and makes it possible to reject null assumption if it is higher. This leads us to analyze series for each country.

We try to take account of temporal structure of variables with this intention, we must test the presence of unit root and if all series are non stationary. The recent approaches adopted by Im, Pesaran and Shin IPS and by Kao are respectively used for unit root and cointegration test. The first consists in carrying out unit root tests on each series by using Augmented Dickey-Fuller, method Dickey and Fuller,; Davidson and MacKinnon,. We obtain then statistics serving to make unit root test for panel by calculating individual statistics ADF average. This value is compared with simulated breaking values provided by IPS. When it is higher than the value given threshold of significance, null assumption of unit root is rejected.

As for used approach by Kao for cointegration, it consists in making individual regressions of ordinary least squares (OLS) of R\&D on COP and carrying out ADF tests on estimated residues of these series Robert Engle and Granger,. The statistics being used to test null assumption of non-cointegration are obtained by calculating the average of ADF statistics previously obtained. It is compared with breaking values provided by Kao and makes it possible to reject null assumption if it is higher. This leads us to analyze series for each country.

\subsection{Econometric Estimation of Dynamic Panel Data Models}

We start with Judson and Own methodology for estimating dynamic panel data models.

\subsubsection{Fixed effect Estimator for Dynamic Panel Data}

Consider the dynamic fixed effects model

$$
y_{i t}=\gamma y_{i, t-1}+x_{i, t}^{\prime} \beta+\eta_{i}+\varepsilon_{i, t} ;|\gamma|<1
$$


Where,

$\eta i$ is a fixed-effect, $x i, t$ is a $(k) \times 1$ vector of exogenous regressors and $\varepsilon i t \sim N(0, \sigma 2 \varepsilon)$ is a random disturbance. Assuming

$\sigma 2 \varepsilon>0$,

$\mathrm{E}(\varepsilon \mathrm{i}, \mathrm{t}, \varepsilon \mathrm{j}, \mathrm{s})=0 \quad \mathrm{i} \neq \mathrm{j}$ or $\mathrm{t} \neq \mathrm{s}$

$\mathrm{E}(\mathrm{xi}, \mathrm{t}, \varepsilon \mathrm{j}, \mathrm{s})=0 \quad \forall \mathrm{i}, \mathrm{j}, \mathrm{t}, \mathrm{s}$

"The fixed effects model is gradually more appropriate than a random effects model for two reasons. First, if the individual effect represents omitted variables, it is likely that these country-specific characteristics are correlated with the other regressors. Second, it is also likely that a typical macro panel will contain most countries of interest and, thus, will not be a random sample from a much larger universe of countries, e.g. an OECD panel contains most OECD countries" Judson and Owen.

The model for yi,t is given in eq.(2); xi,t was generated with

$\mathrm{xi}, \mathrm{t}=\rho \mathrm{xi}, \mathrm{t}-1+\mathrm{vi}, \mathrm{t}$

$\mathrm{vi}, \mathrm{t} \sim \mathrm{N}(0, \sigma 2 \mathrm{v})$

Thus, in addition to $\beta, \rho, \sigma 2 v$ also determine the correlation between yi,t and xi,t. Kiviet defines a signal to noise ratio, $\sigma 2 s$

$\sigma 2 s=\operatorname{Var}(u i, t-\varepsilon i, t), u i, t \equiv y i, t-\frac{1}{1-\gamma} \eta \dot{i}$

and shows that it can be calculated from other parameters of the model as follows

$\sigma_{s}^{2}=\beta^{2} \sigma_{v}^{2}\left[1+\frac{(\gamma+\rho)^{2}}{1+\gamma \rho}[\gamma \rho-1]-(\gamma \rho)^{2}\right]^{-1}+\frac{\gamma^{2}}{1-\gamma_{2}} \sigma_{\varepsilon}^{2}$

The higher the signal-to-noise ratio, the more useful xi,t is in explaining yi,t.

\subsection{2 “Mixed, Fixed and Random” Model for Dynamic Panel Data}

Nair-Reichert and Weinhold, introduced a dynamic panel data model in which the intercepts and the coefficients on the lagged endogenous variables are specific to the cross section units, while the coefficients on the exogenous variables are assumed to be normally distributed across the cross section. Thus the model includes mixture of fixed coefficients and random coefficients, called the "MFR" model. Consider a simple model:

yi, $t=\alpha i+\gamma i y i, t-1+\beta i x i, t+\varepsilon i, t$

Where,

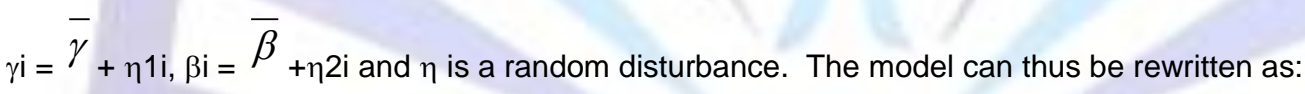

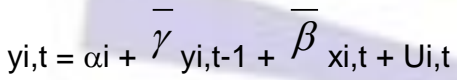

where,

$\mathrm{Ui}, \mathrm{t}=\eta 1, \mathrm{iyi}, \mathrm{t}-1+\eta 2 \mathrm{i} x \mathrm{i}, \mathrm{t}+\varepsilon \mathrm{ci}, \mathrm{t}$

There is clearly a serious problem with this specification as the error term is correlated with the lagged dependent variable. If instead we model the coefficient on the lagged dependant variable as fixed rather than random, but constrain it to be equal across all cross section units so that:

$y i, t=\alpha i+\gamma y i, t-1+\beta i x i, t+\varepsilon i, t$

But there could still be significant biases introduced if in fact the coefficients on lagged dependent variable are not constant across the cross section.

\subsubsection{Fixed Coefficients Approach}

Hurlin and Venet, proposed an extension of the Granger (1969) causality definition to panel data models with fixed coefficients.

Consider the following model: 
$y_{i, t}=\sum_{K=1}^{P} \gamma^{(K)} y_{i, t-K}+\sum_{K=0}^{P} \beta_{i}^{(K)} x_{i, t-K}+V_{i, t}$

with $\mathrm{P} \in \mathrm{N}^{*}$ and $v i, t=\alpha i+\varepsilon i, t$, where $\varepsilon i, t$ are i.i.d. $(0, \sigma 2 \varepsilon)$. Contrary to Nair-Reichert and Weinhold, assume that the autoregressive coefficients $\gamma(\mathrm{k})$ and the regression coefficients slopes $\beta_{i}^{(K)}$ are constant $\forall \mathrm{k} \in[1, \mathrm{P}]$. Also assume that parameters $\gamma(\mathrm{k})$ are identical for all individuals, whereas the regression coefficients slopes $\beta_{i}^{(K)}$ could have an individual dimension. Consider the following assumptions on the error components of vi,t:

i) $\quad E(\alpha i)=E(\varepsilon i, t)=E(\alpha i \varepsilon i, t)=0$

ii)

$\mathrm{E}(\alpha \mathrm{i} \alpha \mathrm{j})=\left[\begin{array}{cc}\sigma_{\alpha}^{2} & i=j \\ 0 & \forall i \neq j\end{array}\right.$

iii)

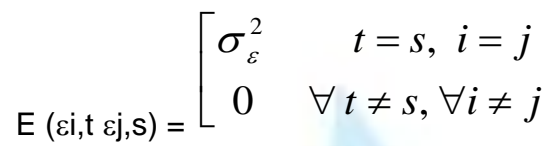

iv) $\quad E(\alpha i x i, s)=E(\varepsilon i, t, x i, s)=0, \forall(s, t)$

In model (10), under assumptions (Al), Hurlin and Venet, consider four principal cases. Let us define $E\left(y_{i, t} / \bar{y}_{i, t}, \bar{x}_{i, t}\right)$ the best linear predictor of yi,t given the set of past values of yi,t, denoted $\bar{y}_{i, t}=\left(y_{i,-p}, \ldots . ., y_{i, 0}, \ldots . ., y_{, t-1}\right)^{\prime}$ and the set of past and present values of xi,t, denoted ${ }^{x_{i, t}}=\left(x_{i,-p}, \ldots . ., x_{i, 0} \ldots \ldots, x_{i,-1}, x_{i, t}\right)^{\prime}$

\subsection{Unit Root and causality in Panel Data}

We start with panel unit root test.

\subsubsection{Panel Unit Root Test}

Levin and Lin, consider the following model:

yi,t=piyi,t-1+Z'it $\gamma+u i, t$

$(\mathrm{i}=1, \ldots, \mathrm{N} ; \mathrm{t}=1, \ldots, \mathrm{T})$

Where,

$\mathrm{Zi}, \mathrm{t}$ is the deterministic component and ui,t is a stationary process. Zi,t could be zero, one, the fixed effects, $\mu \mathrm{i}$, or fixed effect as well as a time trend. The Levin and Lin (LL) tests assume that ui,t are iid $(0, \sigma 2 u)$ and $\rho i=\rho$ for all $i$. The $L L$ test is restrictive in the sense that it requires $\rho$ to be homogeneous across i. Im, Pesaran and Shin (IPS) allow for a heterogeneous coefficient of yi,t-1 and propose an alternative testing procedure based on averaging individual unit root test statistics. IPS suggested an average of the augmented Dickey-Fuller (ADF) tests when ui,t is serially correlated with different series. Correlation properties across cross-sectional units, i.e.; $u_{i, t}=\sum_{j=1}^{p_{i}} \alpha_{i j} u_{i t-j}+\varepsilon_{i t}$. Substituting this ui,t in (11) we get:

$y_{i, t}=\rho_{i} y_{i t-1}+\sum_{j=1}^{p_{i}} \alpha_{i j} \Delta y_{i t-j}+z_{i t}^{\prime} \gamma+\varepsilon_{i t}$

The null hypothesis is:

Ho : $\rho i=1$

for all $\mathrm{i}$ and the alternative hypothesis is:

$\mathrm{Ha}: \rho \mathrm{i}<1$

For at least one i. The IPS t-bar statistic is defined as the average of the individual ADF statistic as:

$\bar{t}=\frac{1}{N} \sum_{i=1}^{N} t_{\rho i}$

where t $\rho$ i is the individual t-statistic of testing $\mathrm{Ho}: \rho \mathrm{i}=1 \mathrm{in}(13)$. It is known for a fixed $\mathrm{N}$ as $\mathrm{T} \rightarrow \infty$ 


$$
t_{\rho i} \Rightarrow \frac{\int_{0}^{1} W_{i z} d W_{i z}}{\left[\int_{0}^{1} W_{i z}^{2}\right]^{1 / 2}}=t_{i T}
$$

IPS assume that tiT are iid are have finite mean variance. Then

$$
\frac{\sqrt{N}\left(\frac{1}{N} \sum_{i=1}^{N} t_{i T}-E\left[t_{i T} / \rho_{i}=1\right)\right.}{\sqrt{\operatorname{Var}\left[t_{i T} / \rho_{i=1}\right]}} \Rightarrow N(0,1)
$$

as $\mathrm{N} \rightarrow \infty$ by the Lindeberg-Levy central limit theorem. Hence

$t_{\text {IPS }}=\frac{\sqrt{N}\left(\bar{t}-E\left[t_{i T} / \rho_{i}=1\right)\right.}{\sqrt{\operatorname{Var}\left[t_{i T} / \rho_{i=1}\right]}} \Rightarrow N(0,1)$

as $T \rightarrow \infty$ followed by $\mathrm{N} \rightarrow \infty$ sequentially. The values of $E[\mathrm{tiT} / \mathrm{\rho} \mathrm{i}=1]$ and $\operatorname{Var}[\mathrm{tiT} / \mathrm{\rho} \mathrm{i}=1]$ have been computed by IPS vis simulations for different values of $\mathrm{T}$ and $\rho^{\prime}$ is.

\subsubsection{Causality test Approach}

\subsubsection{Homogenous Non-Causality Hypothesis}

The first case corresponds to the homogenous non-causality (HNC) Hypothesis. Conditionally to the specific error components of the model, this hypothesis implies that there does not exist any individual causality relationships:

$\forall i \in[1, N] E\left(y_{i, t} / \bar{y}_{i, t}, \alpha_{i}\right)=E\left(y_{i, t} / \bar{y}_{i, t}, \bar{x}_{i, t}, \alpha_{i}\right)$

In model (9), the corresponding test is defined by:

$H_{o}: \beta_{i}^{(K)}=0 \quad \forall_{i} \in[1, N], \forall k \in(1, p)$

$H_{a}: \exists(i, k) / \beta_{i}^{(K)} \neq 0$

In order to test these Np linear restrictions, we compute the following Wald Statistic:

$$
F_{h n c}=\frac{\left(R S S_{2}-R S S_{1}\right) /(N p)}{R S S_{1} /[N T-N(1+p)-p]}
$$

where,

RSS2 denotes the restricted sum of squared residual obtained under Ho and RSS1 corresponds to the residual sum of squares of Model (12). For the ith individual's characteristics into T elements columns, so write

$y_{i_{(T, 1)}}^{(-k)}=\left[\begin{array}{c}y_{i,-k+1} \\ \vdots \\ y_{i, T-k}\end{array}\right] \quad x_{i_{(T, 1)}^{(-k)}}=\left[\begin{array}{c}x_{i-k+1} \\ \vdots \\ x_{i, T-k}\end{array}\right] \quad \varepsilon_{i_{(T, 1)}}=\left[\begin{array}{c}\varepsilon_{i, 1} \\ \vdots \\ \varepsilon_{i, T}\end{array}\right]$

Let us denote ' $e$ ' the $(T, 1)$ unit vector. Then, the model (12) can be written as:

$y_{i}^{(O)}=\sum_{K=1}^{p} \gamma^{(K)} y_{i}^{(K)}+\sum_{K=0}^{p} \beta_{i}^{(K)} x_{i}^{(K)}+e \alpha_{i}+\varepsilon_{i} \forall i \in[1, N]$

introduce here two matrix:

$w_{i_{(T, p)}}=\left[y_{i}^{(1)}: y_{i}^{(2)}: \ldots . .: y_{i}^{(p)}\right]$

$x_{i_{(T, p+1)}}=\left[x_{i}^{(0)}: x_{i}^{(1)}: \ldots \ldots: x_{i}^{(p)}\right]$ 
Finally, the model (13) can be written as:

$$
y=w \gamma+\tilde{x} \beta+\left(I_{N} \otimes e\right) \alpha+\varepsilon
$$

with

$\alpha=(\alpha 1, \alpha 2, \ldots \alpha \mathrm{N})^{\prime}$

In short; If we define

$Z=[w: \tilde{x}]$ and $\Psi^{\prime}=\left(\gamma^{\prime} \beta^{\prime}\right)$ the model (13) can also be written as:

$y=Z \Psi+\left(1_{N} \otimes e\right) \alpha+\varepsilon$

Let us define the following operator $Q$ as:

$Q_{(N T, N T)}=I_{N} \otimes Q_{T}$

with $Q T=1 T-e^{\prime} / T$. Then, the sums of squared residuals of the model (13) obtained under Ho and Ha can be computed as follows:

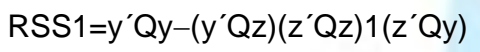

RSS2=y'Qy-(y'Qw) (w'Qw)-1(w'Qy)

For large samples (where $\mathrm{N}$ and $\mathrm{T}$ tend to infinity), under assumptions $\mathrm{Al}$, the Fhnc statistic has a Fischer distribution with $\mathrm{Np}$ and $\mathrm{NT}-\mathrm{N}(1+\mathrm{P})-\mathrm{P}$ degrees of freedom. If the realization of this statistic is not significant, the homogeneous noncausality hypothesis is accepted. This result implies that the variable $\mathrm{x}$ is not causing $\mathrm{y}$ in all the $\mathrm{N}$ countries of the samples. The non-causality result is then totally homogenous and the testing procedure with go no further.

\subsubsection{Homogenous Causality Hypothesis (HC)}

The second case corresponds to the homogenous causality $(\mathrm{HC})$ hypothesis, in which there exists $\mathrm{N}$ causality relationships:

$$
\forall i \in[1, N] E\left(y_{i, t} / \bar{y}_{i, t}, \alpha_{i}\right) \neq E\left(y_{i, t} / \bar{y}_{i, t}, \bar{x}_{i, t}, \alpha_{i}\right)
$$

In this case, assume that the $\mathrm{N}$ individual predictors, obtained conditionally to $\bar{y}_{i, t}, \bar{x}_{i, t}$ and $\alpha \mathrm{i}$, are identical:

$$
\forall(i, j) \in[1, N] E\left(y_{i, t} / \bar{y}_{i, t}, \bar{x}_{i, t}, \alpha_{i}\right)=E\left(y_{i, t} / \bar{y}_{j, t}, \bar{x}_{j, t}, \alpha_{j}\right)
$$

If we reject the null hypothesis of non homogenous causality (HNC), two configurations could appear. The first one corresponds to the overall causality hypothesis (Homogenous causality hypothesis, $\mathrm{HC}$ ) and occurs if all the coefficients $\beta_{i}^{K}$ are identical for all $\mathrm{k}$ and non null. The second on, which is the more plausible, is that some coefficients $\beta_{i}^{K}$ are different for each individual. Thus, after the rejection of the null hypothesis of HNC, the second step of the procedure consists in testing if the regression slope coefficients associated to $x i, t-k$ are identical. This test corresponds to a standard homogeneity test. Formally, the homogenous causality hypothesis $(\mathrm{HC})$ test is the following:

$$
H_{o}: \forall k \in[1, p] / \beta_{i}^{k}=\beta^{k} \forall i \in[1, N]
$$

$H_{a}: \exists k \in[1, p], \exists(i, j) \in[1, N] / \beta_{i}^{k} \neq \beta_{j}^{k}$

The HC hypothesis implies that the coefficients of the lagged explanatory variable $x i, t-k$ are identical for each lag $\mathrm{k}$ and different from Zero. Indeed, if we have rejected, in the previous step, the HNC hypothesis $\beta_{i}^{K}=0 \forall(i, k)$, this standard specification test allows testing the homogenous causality hypothesis.

In order to test the $\mathrm{HC}$ hypothesis, we have to compute the following F statistics:

$$
F_{h c}=\frac{\left(R S S_{3}-R S S_{1}\right) /[p(N-1)}{R S S_{1} /[N T-N(1+p)-p]}
$$

where RSS3 corresponds to the realization of the residual sum of squares obtained in model (13) when one imposes the homogeneity for each lag $\mathrm{k}$ of the coefficients associated to the variable $\mathrm{xi}, \mathrm{t}-\mathrm{k}$. 
As for the HNC hypothesis test, if assume that individual effects $\alpha \mathrm{i}$ are fixed under $\mathrm{Ho}$ and $\mathrm{Ha}$, the MLE estimator corresponds to the fixed effects (FE) estimator. The residual sum of squares RSS1 obtained in model (13) is given by equation (22). Under Ho, the realization of the residual sum of squares RSS3, is then defined by:

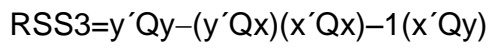

Where $(T N, P+1)$ matrix $x$ is defined by:

$x_{(p+1, T N)}^{\prime}=\left[\begin{array}{llll}x_{1}^{\prime} x_{2}^{\prime} & \ldots & x_{N}^{\prime}\end{array}\right]^{\prime}$

Under assumptions $A 1$, if the Fhc statistics with $\mathrm{P}(\mathrm{N}-1)$ and $\mathrm{NT}-\mathrm{N}(1+\mathrm{P})-\mathrm{P}$ degrees of freedom is not significant, the homogenous causality hypothesis is accepted. This result implies that the variable $\mathrm{x}$ is causing $\mathrm{y}$ in the $\mathrm{N}$ countries of the samples, and that the autoregressive processes are completely homogenous.

\subsubsection{Heterogeneous Causality Hypothesis (HEC)}

The third case corresponds to the heterogeneous causality hypothesis (HEC). Under HEC hypothesis, assume first that there exists at least one individual causality relationships (and at the most $\mathrm{N}$ ), and second that individual predictors, obtained conditionally to $\bar{y}_{i, t}, \bar{x}_{i, t}, \bar{\lambda}_{t}$ and $\alpha \mathrm{i}$, are heterogeneous.

$$
\begin{aligned}
& \exists i \in[1, N] E\left(y_{i, t} / \bar{y}_{i, t}, \alpha_{i}\right) \neq E\left(y_{i, t} / \bar{y}_{i, t}, \bar{x}_{i, t}, \alpha_{i}\right) \\
& \exists(i, j) \in[1, N] E\left(y_{i, t} / \bar{y}_{i, t}, \bar{x}_{i, t}, \alpha_{i}\right) \neq E\left(y_{j, t} / \bar{y}_{j, t}, \bar{x}_{j, t}, \alpha_{j}\right)
\end{aligned}
$$

\subsubsection{Heterogeneous Non-Causality Hypothesis (HENC)}

The last case corresponds to the HENC. In this case, assume that there exists at least one and at the most $\mathrm{N}-1$ equalities of the form

$$
\exists i \in[1, N] E\left(y_{i, t} / \bar{y}_{i, t}, \alpha_{i}\right)=E\left(y_{i, t} / \bar{y}_{i, t}, \bar{x}_{i, t}, \alpha_{i}\right)
$$

If the $\mathrm{HC}$ hypothesis is rejected, it implies that the process is non-homogenous and that no homogenous relationships can be founded. However, it does not imply the lack of any causality relationships between the two variables. It may be possible that for one individual at least, there exists such a relationships. In this case, we get a non-homogenous causality configuration. Thus, the variable $x$ causes the variable $y$ only for a subgroup of the cross-section population.

Clearly, all the interest of the heterogeneous causality hypothesis is determined by the size of this sub-group. So, the third step of the procedure consists in testing the heterogeneous non-causality hypothesis (HENC). For that, we consider the following test:

$$
\begin{aligned}
& H_{o}: \exists i \in[1, N] / \forall k \in[1, p] \beta_{i}^{K}=0 \\
& H_{a}: \forall i \varepsilon[1, N], \exists k \varepsilon[1, N] / \beta_{i}^{K} \neq 0
\end{aligned}
$$

They proposed here to test this last hypothesis with two nested tests. The first test is an individual test realized for each individual. For each individual $\mathrm{i}=1, \ldots, \mathrm{N}$, test the nullity of all the coefficients of the lagged explanatory variable xi,t-k. Then, for each $\mathrm{i}$, test the hypothesis $\beta_{i}^{K}=0, \forall k \in[1, p]$

For that, compute $\mathrm{N}$ statistics:

$$
F_{\text {hene }}^{i}=\frac{\left(R S S_{2, i}-R S S_{1}\right) / p}{R S S_{1} /[N T-N(1+2 p)+p]}
$$

Where RSS2,i corresponds to the realization of the residual sum of squares obtained in model (13), when one imposes the nullity of the $\mathrm{k}$ coefficients associated to the variable xi,t-k only for the individual $\mathrm{i}$. These $\mathrm{N}$ individual tests allow us to identify the individual for which there are no causality relationships. If we assume that individual effects $\alpha i$ are fixed under $\mathrm{Ho}$, the residual sum of squares RSS2,i is then defined by:

RSS2,i=y'Qy-(y'Qzi)(z’iQzi)-1(z'iQy)

where

$$
z_{i}=\left[w: \tilde{x}_{i}\right] \text { with } \tilde{x}_{i} \text { defined by: }
$$




$$
\underset{\{T(N-1),(N-1)(p+1)\}}{\tilde{x}_{i}}=\left[\begin{array}{ccccc}
x_{1} & 0 & \vdots & \vdots & 0 \\
0 & x_{2} & \vdots & \vdots & \vdots \\
\vdots & \vdots & x_{i-1} & \vdots & 0 \\
\vdots & \vdots & \vdots & x_{i+1} & \vdots \\
\vdots & \vdots & \vdots & \vdots & \vdots \\
0 & \vdots & \vdots & \vdots & x_{N}
\end{array}\right]
$$

For a given first order risk $\alpha$, we can compute the corresponding size denoted $n n c(\alpha)$, of the sub-group of individuals for which there is no causality relationships.

A second test of the procedure consists in testing the joint hypothesis that there are no causality relationships for a subgroup of individuals. Let us respectively denote Ic and Inc the index sets corresponding to sub-groups for which there exists a causal relationships and there does not exist a causal relationship. In other words, we consider the following model $\forall \mathrm{t} \in[1, \mathrm{~T}]$ :

$y_{i, t}=\sum_{k=1}^{p} \gamma_{i}^{k} y_{i, t-k}+\sum_{K=0}^{p} \beta_{i}^{k} x_{i, t-k}+v_{i, t}$

With $\beta_{i}^{K}=0$ for $i \in I_{n c}$

Let $n c=\operatorname{dim}(\mathrm{Ic})$ and $\mathrm{nnc}=\operatorname{dim}(\mathrm{Inc})$. Suppose that $\mathrm{nc} / \mathrm{nnc} \rightarrow \theta<\infty$ as $\mathrm{nc}$ and $\mathrm{nnc}$ tend to infinity. One solution to test the HENC hypothesis is to compute the Wald statistic.

$$
F_{\text {henc }}=\frac{\left(R S S_{4}-R S S_{1}\right) /\left(n_{n c} p\right)}{R S S_{1} /\left[N T-N(1+p)-n_{c} p\right]}
$$

Where RSS4 corresponds to realization of the residual sum of squares obtained in model (13) when one imposes the nullity of the k coefficients associated to the variable xi,t-k for the nnc individuals of the Inc sub-group.

If the HENC hypothesis is accepted, it implies that there exists a sub-group of individual for which the variable $x$ does not cause the variable $y$. The dimension of this sub-group is then equal to nnc. On the contrary, if the HENC hypothesis is rejected, it implies that there exists causality relationships between $\mathrm{x}$ and $\mathrm{y}$ for all individual of the panel.

\section{EMPIRICAL RESULTS}

In this section we summarize the results of unit root, cointegration and causality based on panel data tests.

\subsection{Panel Unit Root (IPS) Test Results}

The first step in determining a potentially cointegrated relationship is to test whether the variables involved are stationary or non-stationary, i.e. where the individual series contain unit roots. If all the variables are stationary, then traditional estimation methods can be used to estimate the relationship between the variables, in this case, real GDP per capita (Y) and indicators of financial development (RD, K, $L$ and RJV). If, however, at least one of the series is non-stationary then more care is required. In the first case we assume that none of the individual series in our model contains a trend. Thus, it is assumed for each series, yi,t that $E\left(\Delta y^{*} i t\right)=0$. This means that each series could contain a non-zero intercept but not a time trend. The results based on IPS t-bar statistic are reported in Table 1.

Table 1: Unit Root Tests

\begin{tabular}{|c|c|c|c|c|c|c|c|}
\hline & v-stat & $R h o$ & $P p$ & $A d f$ & $R h o^{1}$ & $P^{1}$ & Adf $^{1}$ \\
\hline$Y, K, L, R D, R J V$ & 2.072 & -2.65 & -6.64 & -3.68 & -4.89 & -9.45 & -4.78 \\
\hline
\end{tabular}

${ }^{1}$ it acts of the tests based on dimension BETWEEN

As it is a one-sided test, a statistic less than $-2.18(-1.99)$ would cause rejection at $1 \%(5 \%)$ of the null of non-stationarity. All series clearly fail to reject the null of unit root. However, our assumption that there is no time trend, especially in the case of real per capita GDP may not be very appropriate. Therefore, we test stationarity again allowing for a time trend. All the series are found to be non-stationary (we fail to reject Ho). Given the presence of non-stationary variables in both specifications, we now proceed to test for Cointegration. 
This section report country-by-country and panel cointegration test results based on the trace test procedure and panel Cointegration Rank test. For each country the cointegrating rank is determined by the sequential likelihood ratio trace test procedure. As seen from Table, in case of real per capita GDP(Y), the most common selected rank is $r=1$ ( 7 of the 10 countries have $r=1$ ), which indicate a Cointegration relation between $Y$ and RJV for these countries. For two countries the rank result is $r=0$ (Indonesia and Sri Lanka) and for Singapore the selected rank is $r=2$. The case for $Y$ and $R D$ shows the selected rank is $r=1$ for 8 out 10 countries.

Table 2: Tests of cointegration of Pedroni

\begin{tabular}{|c|c|c|c|c|c|}
\hline Statistics & Y & RJV & K & L & RD \\
\hline $\begin{array}{c}\text { Levin-Lin ADF- } \\
\text { stat }\end{array}$ & 3.748 & -2.205 & -2.005 & -1.978 & -1.890 \\
\hline IPS ADF-stat & 2.717 & -2.183 & -1.879 & -2.778 & -2.090 \\
\hline
\end{tabular}

From results of Pedroni cointegration tests we can notice that the whole of statistics are lower than breaking value of normal law for a threshold of $5 \%(-1,64)$. So the whole of these tests requires the existence of a cointegration relation. With an aim of carrying out cointegration tests on panel data and to obtain an estimation of cointegration vectors it is necessary to apply an effective method of estimation. Within this framework we can distinguish several techniques with FMOLS method (Full Modified Least Square) used by Pedroni, DOLS method (Dynamic Least Square), GMM method.

\subsection{Panel Causality Tests Results}

Causality tests are used to determine the direction of causality between the variables of the estimated model we are interested especially in the context of our research variables RJV, R\&D and GDP. Because of this, is what the R\&D cause the cooperative $R \& D$, growth or is the cooperative $R \& D$ because the $R \& D$ and growth, or is it a causality in both sense. That is why it is better first of all clarifying the meaning of causality.

We have shown in our research in the master that private spending caused government spending Granger whether past expenditures contribute in explaining public expenditure at time (t). Similarly, public spending than private cause if the past of the variable $R \& D$ public helps in explaining the variable $R \& D$ privately. In the same context, we have demonstrated that $R \& D$ contributes to the explanation of economic growth, causality goes from R\&D to growth and at the same time growth to R\&D.

At this point, what is the direction of causality between R\&D cooperation, R\&D and economic growth and how can we identify causality. In the context of dynamic panels, special attention is paid in recent year's econometricians this question in order to be able to identify causality in dynamic panel based on the work initiated by Engel and Granger.

The work was based on the question of what is the point of switch panel?.

Indeed, this passage is explained by three reasons:

Allows you to compensate for the lack of information in the temporal dimension by taking into account an individual dimension: the heterogeneity of problem behaviors

Part of the literature tends to adapt to the problems of time series panel models: unit root tests, Cointegration tests, VECM, etc. .. Trend related to the emergence of macro panel.

Company more fundamental theory: a causal relationship from $\mathrm{X}$ to $\mathrm{Y}$ must it is specific to an individual (country) or on the contrary a common set of individuals (countries) to be considered valid? So, How to implement the Granger causality (1969) in the panel? To do this, we must consider in general from:

A functional form: linear predictor,

A risk function: mean square error,

The type of process: Process stationary

The horizon of prediction: Toward a period,

The set of information.

It has now become possible to estimate a panel with the dimensions $\mathrm{N}$ and $\mathrm{T}$ are large. Groups can be corporations, industries, regions or countries. Similarly, there are several major advantages for the use of panel data instead of using time series data or cross-sectional. In cases where there is limited time series due to unavailability of data for each country, there may be problems in hypothesis testing. While it is possible to impose some conditions to the parameters of homogeneity across countries a model of panel data provides additional power and allows the detection of some of the different relations not series. The revival of interest in long-term growth and the availability of macroeconomic data, estimating dynamic panel models, has been a key concern for many authors.

The case of Vector Autoregressive panel in a structure in which to test the Granger causality in panel and suggest the use of different instruments and levels. In addition, other instruments have been suggested by several other authors. In this context, it cites as a guide the work of Arellano and Bond, Arellano and Bover,. 
Kiviet shows that panel data models, using the estimation by the method of instrumental variables, often lead to efficient and unbiased estimators. Judson and Owen show that when T = 30 using LSDV can be less than $20 \%$ of the true value of the coefficient to be estimated. A corrected LSDV estimator noted "LSDVC" is the best unbiased estimator, but practical considerations may limit its applicability. The generalized method of moments (GMM) provides in general more efficient estimators. This method is related to Anderson and Hsiao. Finally, a GMM estimator that uses a subset of the lagged variables as instruments increases significantly the efficiency of the estimators. In practice, there are two important econometric problems in estimating dynamic panel models. First, the estimated parameters are biased in models with fixed effects and lagged dependent variables. Second, the assumptions of homogeneity, which are often imposed on the coefficients of the lagged dependent variable, can lead to a bias problem.

The above discussion deals with the first type of bias. Pearson confirms that the bias of homogeneity can cause a bias that cannot be corrected by the estimation using instrumental variables.

From the above discussion, we take the estimator "GMM" of Judson and Owen and Nair-Reichert and Weinhold, comparing the estimators developed fixed coefficients See the first section, for more details. Hurlin and Venet.

Finally, we propose an application of the above models to the question of the relationship between cooperative R\&D (RJV) and economic growth. Cooperation in R\&D has been recently advanced the goal of several studies, instead of economic growth. The link R\&D growth raises two fundamental questions: first, does a close association between economic growth and cooperation in R\&D involve an automatic link between the two? On the other hand, the benefits of economic growth they have an automatic impact on the level of R\&D, and hence cooperation in this area? The answer to both questions is examined through tests of causality.

We test the hypothesis of causality is not homogeneous (HNC) between the cooperative R\&D and economic growth, but also the capital (K), labor (L) and R \& D. We use three different estimators, and those of Hurlin Venet (HV), NairReichert and Weinhold. The GMM estimator is used to test the hypothesis (HNC) above. The results are reported in Appendix 15. Each of the three estimators strongly rejects the hypothesis of HNC, regardless of the choice of about delays, but the values of all the estimators are different in every case. This means that we can assume that the time dimension of the panel $(T=35)$ is sufficient to consider using dynamic panel as insignificant.

First, as part of the study of causality in our panel research, we examine the causality of the cooperative R\&D to GDP per capita.

The results show that the assumption of homogeneous non-causality $(H N C)$ is strongly rejected in all cases (RJV $\rightarrow$ GDP, GDP $R \& D \rightarrow L \rightarrow K \rightarrow G D P$ and GDP), irrespective of the choice of the order of delay $(P=1,2,3)$. This means that the causality of the cord to GDP, R\&D to GDP, $K$ and $L$ to GDP to GDP cannot be rejected for the entire sample of 32 countries. After the rejection of the hypothesis of $\mathrm{HNC}$, we evaluate the hypothesis of homogenous causality (HC). This assumption, which imposes strict homogeneity of the relationship between cooperative R\&D and GDP per capita, is rejected for all the delays.

These results confirm the relative heterogeneity of the sample of 32 countries. Indeed, it is not surprising that these countries do not follow a unique model of cooperation in R\&D and do not show different correlations between cooperation and growth. Given these results, we must consider the heterogeneous causal relations (hypothesis HENC).

These results indicate that the variable RJV causes GDP in the sense of Granger in the countries of the panel (China, India, Japan, Korea, Israel, Canada, USA, Mexico, Brazil ...). However, causal relationships are independent of the delay for only four countries (China, India, Japan, and Korea). For other countries, such as (Algeria and Egypt) there is no causal relationship between the string and GDP. The conclusion about the non-uniform causation and causality is not uniform for different RJV relation to GDP. Results based on FNHC and F HC are the same for the case of R\&D $\rightarrow$ GDP, meaning that the reports of the research and development and economic growth are not homogeneous in our sample. See table 3 and 4.

Test results of reverse causality of GDP on R\&D cooperation, based on FHNC and FHC show that the assumption of homogeneous non-causality and the assumption of uniform causality are strongly rejected for each three cases, GDP $\rightarrow$ $\mathrm{RJV}, \mathrm{RD} \rightarrow \mathrm{GDP}, \mathrm{GDP}$ and GDP $\rightarrow \mathrm{L} \rightarrow \mathrm{K}$. However, we found the causal relationship heterogeneous strong in almost all cases. We observe that the GDP contributes to the improvement of the rope in 19 countries in the sample. . See table 5 and 6.

\section{SUMMARY AND CONCLUDING REMARKS}

We can say generally that through the results of different tests of causality mentioned above we were able to show the importance of cooperation in R\&D in economic growth as a channel of transmission of technological spillovers at the Like other transmission channels such as foreign direct investment, imitation, financial integration etc ...

Our analysis allowed us to study the role played by the international dissemination of knowledge on economic growth. The most important result of our work is that economic integration between two countries could build a guaranteed gain growth momentum among them. Indeed, it is necessary to organize the free movement of knowledge between the partner countries. Dissemination of knowledge can not in any way imply a policy of not protecting intellectual property. Thus, it should be noted that without this type of protection such as patents, innovators would not be able to capture a market rent. Thus, it is important to disseminate knowledge by encouraging cooperation policies in R\&D in order to encourage innovation.

The most remarkable result of our study is to highlight the importance of the international diffusion of knowledge. The organization of cooperative agreements in R\&D between countries is essential for growth in partner countries. At this stage, as well as other transmission channels of spillover technology have a positive impact on growth, cooperation in $R \& D$ is an important determinant of improved technologies and transferring them through a network of partners promotes the free flow of know-how. 
Cooperation is a broadcast channel of externalities. The knowledge, contribute to knowledge creation. Yet this knowledge is externalities for though they are the result of a voluntary transfer, they are used by partners for their internal research. This shows the important role of technological spillovers as an important source of technical progress. In this context, several countries have so opted for a strategy of encouraging cooperation agreements in R\&D through tax incentives and trade, the creation of investment promotion agencies etc..

Indeed, to see how technology is acquired, it should be noted that it is not only physical but also integrated into the product components. For this acquisition of technology is a cumulative process in which learning plays an important role throughout the development and use of technology. For country's competitiveness Development through the improvement of its $R \& D$ science. However, technical progress and innovation are the result not only of R\&D is only one link in a chain involving the wider learning by doing or "Learning by Doing," learning through the use of modern and also learning by interaction, or learning through cooperative $R \& D$ to innovation. Cooperative agreements in $R \& D$ are then a proxy for innovation activities in a sector or a country. This complementarity between different types of learning is a key factor in growth and is a strong indicator of developing nations.

We now know that the interaction between FDI, technology transfer and productivity growth. The factors that determine the effect of FDI is the level of technology, human capital, institutions governing the innovation and learning, the degree of openness. Cooperation in R\&D is not necessarily a substitute for other channels of transmission of know-how such as IDE, but it is an important supplement. We can then suggest the complementarities of cooperation in R\&D and other channels of transmission of knowledge. These complementarities may be located on a purely microeconomic as it may seem at the interface between a micro-level FDI and a macro level: cooperation between nations to encourage R\&D in poor countries where private $R \& D$ is low or almost absent

Gain strategic in R\&D cooperation is preferable to ex post, when property rights are not insured. The approach in terms of strategic externalities explains the proliferation of joint ventures in R\&D. The combination of R\&D to share the cost of innovation with another partner, it also aims to change the market structure, creating strategic externalities. Thus, a covenant is a means of accomplishing a strategic gain.

Finally, we can say that cooperation in R\&D is not just a game between two partner countries, but is part of a game with any two or more countries cooperate in order to exclude other partners in the race for R\&D; innovation and therefore growth.

In other words, cooperation is not just work with but also cooperates to deal with others. In this context, cooperation is a way to support organic growth and mergers - acquisitions. It allows anticipating competitors to catch up, to prevent them from entering the race for innovation, or even avoid any change in established positions. Technology agreements are associated with greater economic performance. Still, the use of cooperative R\&D provides access to information and new skills that can improve the technological capabilities.

The results of unit root test (IPS) indicate that all series contain a unit root. Thus, the traditional econometric procedures cannot be applied to the model. The cointegration test results show a relationship of cointegration between cooperation and economic growth. Results based on tests of causality show that a consistent statistical model cannot represent the effects of cooperative R\&D on economic activity. Our results indicate a causal heterogeneity of cooperation in R\&D to economic growth. The causality of economic growth to cooperation in $R \& D$ is also heterogeneous. Our results provide strong support to the view that economic growth causes the cooperative R\&D.

We examined the cointegration and causality possible cooperation in R\&D and economic growth using data balanced panel of 32 countries covering 35 years 1970-2012. The results by country and IPS-based tests and causality tests in panel Developed by Hurlin and Venet confirm the existence of a positive and significant relationship between cooperative R\&D and economic growth for most sample countries, although for some countries, the coefficients are low. This suggests that for some countries, the effort incentive to undertake R\&D share is still dependent on their economic conditions and encouragement given to R\&D.

As part of our research, we dealt with in terms of the theoretical rationale of cooperation in R\&D. In fact, we have shown that cooperation in R\&D is useful in terms of economic surplus because it can lead to more profit through the increased level of effort in R\&D. We discussed in our theoretical study year the patent system as an instrument of public policy to solve the dilemma of intellectual property rights. Indeed, to overcome the shortcomings of such a system, we have shown that cooperative agreements are a means to encourage investment in R\&D while preserving the diffusion of innovations. These collaborations enable partners to exploit possible synergies. This tends not only to raise the level of investment in R\&D but also their effectiveness reduced duplication of results, which in turn has a beneficial impact on total economic welfare. At this point, the benefits of cooperation in R\&D to stimulate innovative processes are increasingly recognized by governments. So we said well the need to promote cooperative agreements in R\&D. We have also seen that cooperation in R\&D could be understood in different ways. Considering the organizational aspects of learning cooperation, the essential result is the demonstration that the objective through cooperation is better internalizes spillovers.

Cooperative agreements in R\&D can be designed as appropriate structures for sensibility / dissemination. Cooperation is a means to internalize the positive externalities cause a disincentive to invest in research. She then has the effect of increasing the amount of R\&D while ensuring the dissemination of technological knowledge in the partners of the agreement. 
We have shown the one hand, the fundamental role of technological cooperation and on the other hand, technological cooperation can be considered as a mode of governance to improve market efficiency R\&D. Similarly, macro-economic co-operation avoids the under-investment in research and development.

At this stage, technological alliances and joint ventures are a means to encourage investment in R\&D and innovation activities, without questioning the dissemination of research results. This alternative vision to the implementation of a system of protection does not preclude the Schumpeterian analysis. Indeed, it can correct market failures in R\&D. Thus, by monitoring and internalizing the results of $R \& D$ cooperation in $R \& D$, participants are able to capture the profits generated by their research, so that the tendency to under-investment is reduced. Note that the cooperation agreements allow for better dissemination of information that the system of ownership by providing it to all participants in the agreement. We have discussed some aspects as well play a role in the development of cooperative agreements for research and development.

In this perspective, we proposed the following hypothesis: Cooperation in R\&D is a distribution channel of technology spillovers between countries aim to develop a dynamic model of cooperation in R\&D. So cooperation on R\&D is a transmission channel of technology spillovers.

We have shown that the existence of externalities justified and led to advocate a different mode of organization in the form of cooperation. Indeed, technical cooperation is generally regarded as a means of improving the ability to generate new products and new production processes, generating their own competitiveness. The reasons are many. On the one hand, cooperation can partially remedy the many imperfections of markets, and secondly it increases the efficiency of research. Technological cooperation makes it possible to reduce the negative impact of these imperfections on investments in research and development, broadly defined.

In the same context, the theoretical models of cooperation in R\&D focus on the use and protection of intellectual property. Voluntary or involuntary transfer of knowledge spillovers generate significant. The presence of such spillovers implies that a distinction must be made between the drive for innovation and the knowledge base effectively representing the total amount of knowledge available to society. This knowledge base stems from an effort to own R\&D as well as the efforts of $\mathrm{R} \& \mathrm{D}$ of other companies.

Based on models of dynamic panel data model and the choice of premium we have shown that cooperation is a way to support organic growth and mergers - acquisitions. Indeed, it can anticipate the competitors to catch up, to prevent them from entering the race for innovation, or even avoid any change in established positions. Technology agreements are associated with greater economic performance. Still, the use of cooperative R\&D provides access to information and new skills that can improve the technological capabilities.

Table 3: Homogeneous Causality Test $\left(F_{H N C}, F_{H C}\right)$ for CORD to PIB

\begin{tabular}{|c|c|c|c|c|c|c|c|c|}
\hline \multirow{2}{*}{ Retards } & \multicolumn{2}{|c|}{ CORD $\rightarrow$ PIB } & \multicolumn{2}{|c|}{$\mathrm{RD} \rightarrow \mathrm{PIB}$} & \multicolumn{2}{|c|}{$\mathrm{K} \rightarrow \mathrm{PIB}$} & \multicolumn{2}{|c|}{$L \rightarrow P I B$} \\
\hline & $\mathbf{F}_{\text {Hnc }}$ & $\mathbf{F}_{\mathrm{Hc}}$ & $\mathbf{F}_{\mathrm{Hnc}}$ & $F_{\text {Hnc }}$ & $\mathbf{F}_{\mathrm{Hc}}$ & $F_{\mathrm{Hc}}$ & $F_{\text {Hnc }}$ & $F_{\mathrm{Hc}}$ \\
\hline 1 & 3.21 * & 3.79 * & 1.91 * & $1.52^{* *}$ & 1.68 * & 3.07 * & $1.67^{* *}$ & 1.78 * \\
\hline 2 & 4.78 * & 5.69 * & 1.56 * & $1.59^{* \star}$ & 1.52 * & 3.25 * & $1.53^{* *}$ & 1.76 * \\
\hline 3 & 3.69 * & 5.49 * & 2.56 * & 1.81 * & 2.04 * & $2.57^{*}$ & 1.79 * & 2.12 * \\
\hline
\end{tabular}

Table 4: Homogeneous Causality Test (Fhnc, Fhc) for PIB to CORD

\begin{tabular}{|c|c|c|c|c|c|c|c|c|}
\hline \multirow{2}{*}{ Retards } & \multicolumn{2}{|c|}{ PIB $\rightarrow$ CORD } & \multicolumn{2}{|c|}{$\mathrm{PIB} \rightarrow \mathrm{RD}$} & \multicolumn{2}{|c|}{$\mathrm{PIB} \rightarrow \mathrm{K}$} & \multicolumn{2}{|c|}{$\mathrm{PIB} \rightarrow \mathrm{L}$} \\
\hline & $\mathbf{F}_{\text {Hnc }}$ & $\mathbf{F}_{\mathrm{Hc}}$ & $F_{\text {Hnc }}$ & $\mathbf{F}_{\text {Hnc }}$ & $\mathbf{F}_{\mathrm{Hc}}$ & $\mathbf{F}_{\mathrm{Hc}}$ & $\mathbf{F}_{\text {Hnc }}$ & $\mathbf{F}_{\mathrm{Hc}}$ \\
\hline 1 & $3.10^{*}$ & $5.56^{*}$ & $2.23^{*}$ & $3.29^{*}$ & $2.01^{*}$ & $3.71^{*}$ & $3.10^{*}$ & $5.56^{\star}$ \\
\hline 2 & $2.56^{*}$ & $5.1^{*}$ & $2.31^{*}$ & $2.66^{*}$ & $2.09^{*}$ & $2.78^{*}$ & $2.56^{\star}$ & $5.1^{*}$ \\
\hline 3 & $2.71^{*}$ & $3.54^{*}$ & $3.16^{*}$ & $2.76^{*}$ & $1.65^{*}$ & $2.91^{*}$ & $2.23^{*}$ & $3.54^{*}$ \\
\hline
\end{tabular}

* Significaticant level $5 \%$

** Significaticant level $10 \%$ 
ISSN 2278-5612

Table 5: Heterogeneous causality test ( $F_{\text {HENC }}$ ) for CORD to PIB

\begin{tabular}{|c|c|c|c|c|c|c|c|c|c|c|c|c|}
\hline & \multicolumn{3}{|c|}{ CORD $\square$ PIB } & \multicolumn{3}{|c|}{ RD $\square$ PIB } & \multicolumn{3}{|c|}{$\mathbf{K} \square \mathbf{P I B}$} & \multicolumn{3}{|c|}{$\mathrm{L} \square \mathrm{PIB}$} \\
\hline Pays & 1 & 2 & 3 & 1 & 2 & 3 & 1 & 2 & 3 & 1 & 2 & 3 \\
\hline Australie & $18.91^{*}$ & $7.41^{*}$ & $4.82^{*}$ & $3.67^{*}$ & $2.52^{\star *}$ & 0.08 & $6.85^{\star}$ & 0.57 & 0.81 & 0.47 & 0.11 & 0.84 \\
\hline Belgique & $13.97^{\star}$ & $4.65^{\star}$ & $2.61^{* *}$ & $3.14^{*}$ & $2.86^{\star}$ & $10.95^{\star}$ & $2.66^{\star *}$ & 1.69 & $3.1^{*}$ & $4.13^{\star}$ & $10.95^{\star}$ & $2.66^{* *}$ \\
\hline Canada & 0.42 & 0.68 & 0.77 & 0.43 & 1.98 & 0.015 & 0.09 & 0.15 & 0.16 & 0.41 & 0.11 & 0.01 \\
\hline Danemark & 1.02 & 0.45 & 0.49 & 0.45 & 0.95 & 2.28 & 1.99 & 1.66 & 1.68 & 1.168 & $3.15^{\star *}$ & $2.81^{\star *}$ \\
\hline Finlande & 0.28 & 0.35 & 0.3 & 0.45 & 0.96 & 0.03 & 1.18 & $3.67^{*}$ & $2.41^{* *}$ & $2.16^{\star *}$ & 0.09 & 1.16 \\
\hline France & 1.16 & 0.78 & 0.61 & 0.54 & 0.17 & 2.27 & 1.02 & 0.78 & 0.86 & 1.42 & $5.11^{*}$ & 1.35 \\
\hline Allemagne & 1.16 & 0.33 & 0.96 & $4.21^{*}$ & 0.57 & 1.92 & 1.14 & 0.48 & 0.46 & 0.27 & $5.24^{*}$ & $5.8^{*}$ \\
\hline Grèce & $6.94^{*}$ & $7.71^{*}$ & $4.80^{*}$ & $4.21^{*}$ & $4.95^{\star}$ & $6.77^{\star}$ & 1.52 & 1.08 & 0.82 & 1.68 & 0.08 & 1.36 \\
\hline L'Iceland & 0.02 & 0.51 & 0.94 & $2.19^{*}$ & 2.02 & 2.27 & 0.74 & 0.56 & 1.21 & 1.58 & 2.4 & 0.91 \\
\hline L'Ireland & $3.85^{\star *}$ & $6.40^{*}$ & $2.62^{\star *}$ & $2.72^{*}$ & $2.31^{*}$ & 0.94 & $8.04^{*}$ & $7.6^{*}$ & $2.52^{* *}$ & $3.31^{*}$ & 0.93 & $8.03^{*}$ \\
\hline Italie & 0.56 & 0.81 & 0.46 & 2.34 & $2.54^{* *}$ & 1.87 & $2.18^{\star *}$ & 1.61 & 2.25 & 0.83 & 0.74 & 0.64 \\
\hline Japon & 1.68 & $3.11^{*}$ & $4.13^{*}$ & 1.38 & 0.7 & 0.51 & 0.3 & 0.21 & 0.01 & 0.04 & 0.06 & 0.38 \\
\hline Corée & 0.08 & 0.06 & 1.62 & $10.2^{*}$ & $2.58^{\star *}$ & 0.81 & 0.84 & 0.74 & $2.94^{*}$ & 1.12 & 1.49 & 0.91 \\
\hline Mexique & 2.08 & $2.78^{*}$ & 1.65 & 1.21 & $4.34^{*}$ & $2.78^{\star *}$ & 1.62 & 1.48 & 0.04 & 0.92 & 0.63 & 0.31 \\
\hline Hollande & $3.01^{*}$ & 1.97 & 2.01 & 0.59 & 0.09 & 0.09 & 0.38 & 0.38 & 0.25 & 0.33 & 0.18 & 0.14 \\
\hline N-Zélande & 1.31 & 1.15 & 1.51 & 0.26 & 0.05 & 0.53 & 0.32 & 0.21 & 0.07 & 0.08 & 0.28 & 0.32 \\
\hline Norvège & 2.21 & $2.18^{\star *}$ & 1.69 & 2.02 & 0.48 & 0.63 & 0.51 & 0.73 & 0.07 & 0.24 & 0.58 & 0.93 \\
\hline Portugal & 1.49 & 1.04 & 0.51 & 1.02 & 0.14 & 0.33 & 0.29 & 0.71 & 0.37 & 0.05 & 0.22 & $2.18^{\star \star}$ \\
\hline
\end{tabular}

1192 | P a g e

Dece m ber, 2013 


\begin{tabular}{|c|c|c|c|c|c|c|c|c|c|c|c|c|}
\hline Espagne & 0.71 & 1.36 & 1.86 & 1.75 & 1.23 & 1.6 & 0.99 & 0.72 & 0.15 & 0.21 & 0.41 & 0.41 \\
\hline Suède & $7.67^{*}$ & $2.52^{* *}$ & $3.29^{*}$ & 2.31 & 1.08 & 0.71 & 0.41 & 0.32 & 1.75 & 0.36 & 0.16 & 0.34 \\
\hline Suisse & 0.94 & 1.24 & $2.72^{*}$ & 0.82 & 0.71 & $4.91^{*}$ & $4.48^{*}$ & $2.92^{*}$ & $3.43^{\star}$ & 1.64 & 0.98 & 0.64 \\
\hline Turquie & 0.91 & 0.83 & 0.79 & 0.71 & 0.23 & 0.13 & 0.31 & 0.32 & 0.56 & 0.07 & 0.29 & 0.54 \\
\hline Bretagne & 0.39 & 0.22 & 0.72 & 1.71 & 0.28 & 0.18 & 1.58 & 1.23 & 1.12 & 0 & 0.2 & 0.51 \\
\hline USA & $5.54^{\star}$ & $2.89^{\star}$ & $2.43^{* *}$ & 0.69 & $4.92^{*}$ & $2.41^{* *}$ & 1.12 & $2.56^{\star *}$ & 1.91 & 1.64 & $2.99^{*}$ & 1.69 \\
\hline Tunisie & 1.93 & 1.47 & 0.74 & $4.97^{*}$ & $2.71^{\star *}$ & 1.81 & 1.18 & 0.92 & $5.12^{*}$ & 2.31 & 1.68 & 0.94 \\
\hline Inde & 0.81 & 0.98 & 0.72 & 0.73 & 0.29 & 0.56 & 0.06 & 0.25 & 0.51 & 1.46 & 1.75 & $2.45^{\star *}$ \\
\hline Israël & $16.37^{\star}$ & $7.14^{*}$ & $5.14^{*}$ & 0.35 & 1.71 & 0.48 & 0.44 & 0.49 & 0.81 & 0.51 & 0.35 & 0.33 \\
\hline Chine & 2.01 & 1.56 & 1.59 & 0.05 & 0.12 & 0.14 & 0.82 & 0.99 & 0.48 & 0.17 & 0.22 & 0.63 \\
\hline Brésil & 0.55 & 1.75 & 1.05 & 0.28 & 0.45 & 0.34 & $4.11^{*}$ & 1.17 & $3.26^{* *}$ & 0.28 & 0.51 & 0.45 \\
\hline Maroc & $2.97^{* *}$ & 0.11 & 2.26 & 0.23 & $2.92^{\star *}$ & $3.22^{* *}$ & 0.97 & $3.24^{\star *}$ & $2.97^{* *}$ & 1.39 & 1.11 & 1.11 \\
\hline Algérie & $8.76^{*}$ & 2.15 & 0.46 & 0.24 & $3.21^{* *}$ & 2.04 & 1.73 & 2.36 & 0.99 & 1.05 & 0.93 & 0.62 \\
\hline Egypte & 1.27 & $4.99^{*}$ & $6.31^{*}$ & 0.61 & $4.31^{*}$ & $6.78^{\star}$ & 1.48 & 0.003 & $19.43^{*}$ & $4.78^{*}$ & $3.72^{*}$ & $5.38^{*}$ \\
\hline
\end{tabular}

Table 6: Heterogeneous causality test ( $F_{\text {HENC }}$ ) for PIB to CORD

\begin{tabular}{|c|c|c|c|c|c|c|c|c|c|c|c|c|}
\hline Retards & \multicolumn{3}{|c|}{$\mathrm{PIB} \square \mathrm{CORD}$} & \multicolumn{3}{|c|}{$\mathrm{PIB} \square \mathrm{RD}$} & \multicolumn{3}{|c|}{ PIB $\square \mathrm{K}$} & \multicolumn{3}{|c|}{$\mathrm{PIB} \square \mathrm{L}$} \\
\hline Pays & 1 & 2 & 3 & 1 & 2 & 3 & 1 & 2 & 3 & 1 & 2 & 3 \\
\hline Australie & 0.28 & 1.52 & 0.13 & 0.356 & 0.38 & $7.53^{*}$ & $6.03^{*}$ & $7.27^{*}$ & 1.82 & $4.15^{*}$ & $7.45^{\star}$ & $5.82^{*}$ \\
\hline Belgique & 0.01 & 1.67 & 1.02 & 1.48 & $2.13^{\star *}$ & 0.85 & 0.48 & 0.72 & 0.22 & 0.26 & 0.85 & 0.48 \\
\hline
\end{tabular}


ISSN 2278-5612

\begin{tabular}{|c|c|c|c|c|c|c|c|c|c|c|c|c|}
\hline Canada & $14.75^{\star}$ & $7.31^{*}$ & $5.05^{\star}$ & $3.25^{\star}$ & $3.65^{\star}$ & 0.29 & 1.08 & $4.40^{\star}$ & $2.81^{\star}$ & $2.39^{* *}$ & 0.29 & 0.47 \\
\hline Danemark & 1.67 & $23.78^{*}$ & $13.63^{*}$ & $8.42^{*}$ & $11.62^{*}$ & 2.46 & $15.59^{*}$ & $11.78^{*}$ & $8.04^{*}$ & $4.97^{*}$ & 0.67 & 1.85 \\
\hline Finlande & $4.45^{\star}$ & $5.04^{*}$ & 2.11 & 1.72 & 1.87 & $4.37^{\star}$ & 2.42 & 1.31 & 1.27 & 0.78 & $4.97^{\star}$ & $3.43^{\star *}$ \\
\hline France & 1.7 & $3.23^{\star *}$ & $3.91^{*}$ & $5.08^{*}$ & $2.35^{\star *}$ & 0.93 & 1.05 & 1.95 & 1.13 & 0.61 & 0.58 & 1.09 \\
\hline Allemagne & $7.60^{*}$ & $2.52^{* *}$ & 1.84 & 1.03 & 0.46 & $4.36^{*}$ & 0.85 & 1.39 & $2.18^{* *}$ & 1.8 & 1.88 & $2.63^{* *}$ \\
\hline Grèce & 2.11 & $6.48^{*}$ & $5.86^{*}$ & $3.97^{\star}$ & $5.45^{\star}$ & 1.79 & $6.01^{*}$ & $6.44^{*}$ & $5.12^{*}$ & $4.71^{*}$ & 2.5 & 1.76 \\
\hline Iceland & 1.28 & 2.29 & $2.81^{* *}$ & 1.53 & 0.82 & $3.81^{* *}$ & $2.81^{* *}$ & 1.38 & 0.89 & 0.64 & $3.57^{\star *}$ & $2.59^{* *}$ \\
\hline Ireland & 0.002 & $15.58^{*}$ & $8.63^{*}$ & $11.2^{*}$ & $10.52^{*}$ & $23.47^{*}$ & $35.56^{*}$ & $20.25^{*}$ & $12.91^{*}$ & $10.96^{\star}$ & $23.43^{*}$ & $35.39 *$ \\
\hline Italie & $7.15^{\star}$ & 1.7 & $4.14^{*}$ & 1.54 & 0.85 & 0.59 & 1.05 & 1.39 & 2.31 & 1.07 & 0.74 & 0.46 \\
\hline Japon & 0.72 & 0.22 & 0.26 & 0.85 & 0.06 & 0.15 & 0.96 & 0.74 & 1.91 & 0.36 & 0.41 & 0.28 \\
\hline Corèe & $4.54^{*}$ & $3.03^{*}$ & $3.05^{*}$ & 1.73 & 0.44 & 0.88 & 1.04 & 0.67 & 0.27 & 0.29 & 0.59 & 0.43 \\
\hline Mexique & $2.39^{* *}$ & $3.12^{*}$ & 2.01 & 0.42 & $2.85^{\star \star}$ & $2.84^{\star *}$ & $6.71^{*}$ & $7.61^{*}$ & 0.4 & 0.27 & 0.71 & 0.87 \\
\hline Hollande & 1.81 & 1.44 & 1.03 & 2.34 & 0.55 & 1.24 & 0.99 & 0.63 & 1.09 & 2.1 & 1.57 & $3.11^{*}$ \\
\hline N-Zélande & 1.59 & 0.73 & 0.59 & $3.31^{* *}$ & $4.78^{\star}$ & $3.91^{*}$ & 0.17 & 0.07 & 0.01 & 0.15 & 0.21 & 0.21 \\
\hline Norvège & $3.21^{*}$ & $2.18^{* *}$ & $2.25^{\star *}$ & 0.04 & 0.07 & 1.92 & 0.8 & 0.61 & 0.03 & 0.24 & 1.02 & 0.54 \\
\hline Portugal & $4.31^{*}$ & $7.06^{*}$ & $10.26^{*}$ & $2.96^{\star \star}$ & 0.43 & 1.01 & $2.38^{* *}$ & 1.61 & 0.002 & 0.04 & 0.34 & 0.64 \\
\hline Espagne & 1.35 & 0.91 & 0.04 & 0.39 & $2.73^{* *}$ & $2.67^{* *}$ & 1.87 & 1.29 & 0.134 & 0.34 & $2.41^{* *}$ & $2.54^{* *}$ \\
\hline Suède & $20.19^{*}$ & $12.96^{*}$ & $10.05^{*}$ & $3.91^{* *}$ & 0.92 & 0.2 & $3.16^{*}$ & 1.96 & 0.17 & 0.23 & 0.18 & 0.26 \\
\hline Suisse & 1.91 & 0.004 & 0.99 & 0.28 & 0.56 & 0.27 & 1.01 & 0.21 & 2.17 & 0.32 & 1.39 & 1.38 \\
\hline Turquie & 0.97 & 0.35 & 0.18 & 0.16 & 0.414 & 1.27 & 0.93 & 0.51 & $3.67^{\star *}$ & 1.84 & 0.74 & $2.31^{* *}$ \\
\hline
\end{tabular}

1194 | P a g e 


\begin{tabular}{|l|c|c|c|c|c|c|c|c|c|c|c|c|}
\hline Bretagne & 0.64 & 0.52 & 0.24 & 0.12 & 0.23 & 0.94 & 0.86 & 1.54 & 0.51 & 0.26 & 0.22 & 0.23 \\
\hline USA & 0.66 & 1.84 & $2.99^{\star *}$ & 0.24 & 0.17 & 0.76 & 0.2 & 1.79 & 0.003 & 0.04 & 0.48 & 0.72 \\
\hline Tunisie & 0.77 & 0.67 & 0.24 & 1.85 & 1.58 & 1.09 & 0.16 & 1.34 & $5.42^{\star}$ & 2.48 & 1.74 & 0.44 \\
\hline Inde & 0.16 & 0.01 & 0.28 & 1.1 & 1.14 & $3.84^{*}$ & 1.33 & 0.41 & 0.319 & 0.12 & 0.1 & 0.29 \\
\hline Israël & 0.35 & 0.38 & 0.19 & 1.38 & 0.14 & 0.11 & 0.88 & 0.38 & 0.74 & 0.16 & 0.26 & 1.24 \\
\hline Chine & 0.61 & $3.81^{\star *}$ & 2.18 & 0.81 & 0.91 & 1.81 & $3.58^{\star *}$ & 1.91 & 1.51 & 0.21 & 0.19 & 0.19 \\
\hline Brésil & 0.73 & 0.002 & 0.04 & 1.87 & $2.47^{\star \star}$ & $2.46^{\star *}$ & 1.41 & 0.94 & 0.619 & 0.3 & $3.87^{\star}$ & 1.67 \\
\hline Maroc & 1.69 & 0.43 & 0.71 & 0.77 & 0.52 & 0.32 & 0.24 & 0.66 & 0.44 & 0.38 & 0.48 & 1.044 \\
\hline Algérie & 1.56 & 0.05 & 0.51 & 0.42 & 1.97 & 0.85 & 0.1 & 0.55 & 0.62 & 0.86 & 0.67 & 0.46 \\
\hline Egypte & 1.91 & $4.35^{\star}$ & 2.25 & 1.65 & 0.88 & 1.11 & 2.32 & 1.05 & 0.68 & 1.07 & 0.78 & 0.62 \\
\hline
\end{tabular}

ISSN 2278-5612

* Significatifcant level $5 \%$

** Significaticant level $10 \%$ 


\section{ACKNOWLEDGMENTS}

The authors wish to acknowledge their appreciation towards the reviewers and the editor for their valuable comments and suggestions which have enhanced the quality of the final paper. Our thanks to the experts who have contributed towards development of the template.

\section{REFERENCES}

[1] Antonelli, M. (1994) 'Ttechnological districts localized spillovers and productivity growth. The Italian evidence on technological externalities in the core regions', International Review of Applied Economics, pp. 18-30.

[2] Arellano, M. and Bond, S. (1991) 'Some test of specification for panel data: Monte Carlo evidence and application to employment equations', Review of Economic Studies, Vol. 58, pp. 277-297.

[3] Arellano, M. and Bond, S. (1998) 'Dynamic panel data Estimating using DPD98-A Guide for users', institute for Fiscal Studies, mimeo

[4] Baumol, W. J. (1992) 'Horizontal collusion and innovation', Economic Journal, Vol.102, pp, 129-137.

[5] Baumol, W. J. (1997) 'Pareto optimal sizes of innovation spillovers', Research Report, pp. 97-42, The C.V. Starr Centre for Applied Economics, Department of Economics, New York University.

[6] Baumol. W. J. (1993) 'The Mechanisms of Technology Transfer, II: Technology Consortia in Complementary Innovations' In Entrepreneurship, Management, and the Structure of Payoffs. MIT Press: Cambridge MA, pp, 193-222.

[7] Broekel, T. and Boschma R. (2011): Knowledge networks in Dutch aviation industry: the proximity paradox, Journal of Economic Geography, forthcoming.

[8] Broekel, T., Buerger, M., Brenner, T. (2010) An investigation of the relation between cooperation and the innovative success of German regions. Papers in Evolutionary Economic Geography. 10.11, Utrecht University, Utrecht.

[9] Broekel, T. and Graf, H. (2012): Public research intensity and the structure of German R\&D networks: A comparison of ten technologies. Economics of Innovation and New Technology, Economics of Innovation and New Technology 21/4, 345-372.

[10] Cassiman, B. and Veugelers, R. (2002) 'R\&D cooperation and spillovers: some empirical evidence from Belgium', American Economic Review, Vol. 92, N. 4, pp. 1169-1184.

[11] Combe, E. (1998) 'Pour quoi les firmes s'allient-elles ? Un Etat de l'art', Revue d'économie Politique, Vol. 4 N. 108, pp. 433-475.

[12] Cozzi, G. (1999) 'R\&D cooperation and growth', Journal of Economic Theory, Vol. 86, pp. 17-49.

[13] Crampes, C. and Encaoua, D. (2001) 'Microéconomie de l'innovation', Série verte, Bargaining over monetary policy and the desirability of central bank independence, V01067.

[14] D'aspremont, C. and Jacquemin, A. (1988) 'Cooperative and non cooperative R\&D in duopoly with spillovers', American Economic Review, Vol. 5, N. 78. pp. 1133-1137.

[15] D'aspremont, C. and Jacquemin, A. (1990) 'Cooperative and Non-cooperative R\&D in Duopoly with Spillovers: Erratum', American Economic Review, Vol. 78, pp. 1133-1137.

[16] Davidson, R. and MacKinnon, J.G. (1992) 'Regression-Based Methods for Using Control and Antithetic Variates in Monte Carlo Experiments', Journal of Econometrics, Vol. 54, pp. 203-222.

[17] Dickey, D. and Fuller, W. (1979), "Distribution of the Estimators for Autoregressive Time Series with a Unit Root", Journal of the American Statistical Association, 74, 427 - 431.

[18] Gallie, E.P. (2003) 'La coopération, vecteur d'externalités de connaissances', Colloque "Economie de la firme: quelles nouveautés? Annecy, 17-18.

[19] Geroski, P.A. (1992) 'Vertical relations between firms and industrial policy', Economic Journal, Vol. 102, N. 410, pp. 138-147.

[20] Hurlin, C. et Venet, B.(2001), "Granger Causality Tests in Panel Data Models with Fixed Coefficients", Cahier de Recherche EURISCO n²001-09, Université Paris IX Dauphine. 
[21] Im, K., Pesaran, H. and Shin, Y. (2003) 'Testing for unit roots in heterogeneous panels', Journal of Econometrics, Vol. 115, pp. 53-74.

[22] Irwin, D. and Klenow, P. (1996) 'High-Tech R\&D Subsidies: Estimating the effects of SEMATECH', Journal of International Economics', Vol. 40, pp. 323-344.

[23] Judson, R. and Owen, A. 1999. Estimating dynamic panel data models: a guide for macroeconomic. Economics Letters 65, 9-15.

[24] Kao, C. (1999), "Spurious regression and residual based tests for co integration in panel data", Journal of Econometrics pp, 1-44.

[25] Katz, M.L. (1986) 'An analysis of cooperative research and development', RAND Journal of Economics', Vol. 17, N. 4, pp. 527-543.

[26] Kiviet Jan. F (1995) Neglected Dynamics in Dynamic Panel Data Models; Consequences and Detection in Finite Samples, (with I.T. van den Doel), Statistica Neerlandica, 49, 343-361.

[27] Levin, A., Lin, C. and Chu, C.J. (2002) 'Unit root tests in panel data: Asymptotic and nite-sample properties', Journal of Econometrics, Vol. 108, pp. 1-24.

[28] Levin, R., Cohen, W. and Mowery, D. (1985) 'R\&D appropriability, opportunity and market structure: New evidence on some Schumpeterian hypotheses', American Economic Review', Vol. 75, pp. 20-24.

[29] Levin, R., Klevorick, N.R. and Winter, S. (1987) 'Appropriating returns from industrial research and development in Baily, M. and Winston, C. redactors 'Brooking papers on Economic activity', Wachington, the brooking institution.

[30] March, 1991, Exploration and Exploitation in Organizational learning, Organization Science, V2, p 71. 3.

[31] McKelvie, A. and Wiklund, J. (2010): Advancing Firm Growth Research: A Focus on Growth Mode Instead of Growth Rate, Entrepreneurship: Theory \& Practice, 34(2):261-288.

[32] Mowery, D. and Rosenberg, N. (1989) 'Technology and the pursuit of economic growth', Cambridge University Press.

[33] Mowery, D., Oxley, C. and Silverman, B. (1996) 'Strategic Alliances and Inter-firm Knowledge Transfer', Strategic Management Journal, Vo1. 7, pp. 77-91I.

[34] Nair-Reichert, U.; Weinhold, D.; (2001) Causality tests for cross-country panels: a new look at FDI and economic growth in developing countries. Oxford Bulletin of Economics and Statistics, 63 (2) pp. 153-171.

[35] Nooteboom, B. (1999) 'Inter-firm alliances-analysis and design', London, Routledge.

[36] Robert F. Engle; C. W. J. Granger (1987), Co-Integration and Error Correction: Representation, Estimation, and Testing Econometrica, Vol. 55, No. 2. pp. 251-276.

\section{Author' biography with Photo}

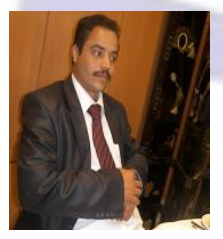

Tarek SADRAOUI Assistant Professor in Quantitative methods Laboratory of modeling and optimization (MODELIS), Higher Institute of Business Administration E-Mail: tarek.sadraoui@gmail.com Phone: 0021698325130

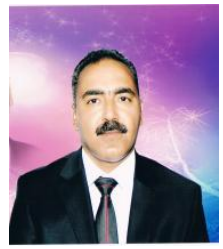

Tarek Ben Ali, Assistant Professor in Economic Sciences Higher Institute of Business Administration E-Mail: tarek.sadraoui@gmail.com 